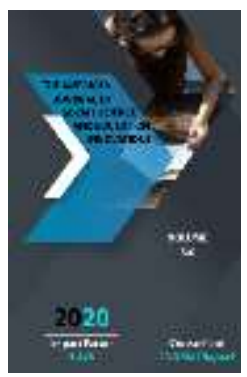

Journal Website: http://usajournalshub.c om/index,php/tajssei

Copyright: Original content from this work may be used under the terms of the creative commons attributes 4.0 licence.

\section{Modeling The Psychological Competence Of Higher Education Leaders (In The Example Of Mid-Level Management Staff)}

\author{
Hayitov Oybek Eshboevich \\ Candidate Of Psychological Sciences, Associate Professor, Deputy Director For Scientific And \\ Methodological Work, The Center Of Scientifically-Methodical Providing For Retraining And \\ Professional Development Of Specialists In Physical Culture And Sport, Tashkent, Republic Of \\ Uzbekistan
}

\title{
ABSTRACT
}

This article discusses the modeling of psychological competence of higher education management staff. A number of political and social events taking place in the world community today show that the 21st century has been predicted to be a century of high information technologies and a sharp rise in intellectual level. It is precisely these details that require the reform of human relations, including in the field of management, the choice of subtle and unique ways of dealing with people of high intellectual level and influencing them effectively.

\section{KEYWORDS}

social psychology, management psychology, subject, object, modeling, psychological competence, leader, communicative, psychological, professional, socio-psychological, socio-perceptive, conflict.

\section{INTRODUCTION}

The tradition of psychological assessment of managers, the development of a set of qualities necessary for them, the study of the correct selection of candidates exists in the field of social psychology. Historically, the seriousness and relevance of scientific research in this area has led to the emergence of an independent field called management psychology. From the analysis, it is known that a number of researchers from developed countries who have conducted research in this area have some experience in researching 
optimal work methods specific to the leader. For example, in 1939 K. Levin, R. Lippman, R. White's [1. 271-301], the theory of autocratic, democratic, and liberal forms of government, has been extensively analyzed by many scholars around the world in subsequent studies. Opinions about both the pros and cons of each management style are validated. It is also recognized that the effectiveness of a particular management style depends on the skills and levels of employees. In illuminating this situation, first of all, the relationship between the subject and the object of management that arises during the implementation of the goals and objectives of management is interpreted.

In the middle of the twentieth century, the principle of modeling was first applied in the field of management, and now it is recognized as one of the advanced principles of the science of psychology. The global changes that have taken place in the socio-economic sphere of our society over the past four years, that is, the transition to a new era, are, on the one hand, the result of natural development and, on the other hand, a new and unknown situation. Therefore, knowing that the transition from one stage to another is going to be a crisis in itself helps us to take a fresh look at such situations, to realize that these difficulties are temporary, and to overcome the crisis interval with more confidence. Therefore, the science of social psychology puts the need to move from theoretical to abstract thinking in solving the above problems, to understand the problem of governing entities, that is, to have a logically holistic worldview, which should be known as an active member of society, regardless of profession and specialization. The ability to understand and evaluate according to the economic image of nature and society and its dynamics, in short, requires the study of both practical and theoretical aspects of psychological ethnopsychological values.

\section{THE MAIN FINDINGS AND RESULTS}

According to statistics, as of January 1, 2020, the number of heads of legal entities operating in the Republic of Uzbekistan (excluding heads of small businesses and non-governmental organizations) is 149,468. In particular, 132,944 of them are leaders with higher education.

Also, if we analyze by age, those under 25 1,$716 ; 25$ to 30 years old $-12,786$; 31 to 39 years old - 48,104; 40 to 49 years old - 47,950; 50 - 54 years old - 23,936 people; The number of people aged 55 and older is 14,988 [2].

Also, as of June 1, 2020, there are 121 higher education institutions in the country, excluding military and religious educational institutions, of which 95 are local and 26 are foreign higher education institutions and their branches. In 2020 , the number of full-time management staff in universities will be 4,010. In particular, 1,495 of them are heads of departments, 1,899 are heads of departments, 406 are deans of faculties, 210 are vice-rectors.

It should be noted that 1,901 management staff, or $47.4 \%$, are mid-level management staff [3].

The future of 33,633 professors and more than $464,740,000$ students is directly or indirectly dependent on the effectiveness of mid-level management staff. Today, improving the quality of education is one of the most pressing issues of any modern society.

Experts in the field, while analyzing the management process from a socio- 
psychological point of view, emphasize that it is possible to imagine the leader as a subject of management, and the employee and the work team as an object. Again, in their view, the leader puts on the agenda the need to organize and self-manage his activities, to understand him not only as a subject of management, but also as an object, and this can be seen mainly in the activities of middle managers. Studies show that mid-level managers, who take on the main weight in any organization, need to have more specialized skills. They are individuals who are attentive to work, responsible, and capable of analyzing large amounts of data quantitatively and qualitatively. Therefore, the professional development of mid-level managers, the acquisition of self-management skills, in short, the ability of the leader to successfully work together in a system of personal relationships with subordinates, that is, the formation of management competence requires modeling, becoming one of the main problems in the form of social expectation, which provides the regulation of interactions and cooperation in the group environment and in intergroup relations.

As noted in the literature, modeling is the process of studying a real system, which involves the study of the structure of the model, the study of its properties, and the transfer of the obtained data to the modeled system. Modeling also involves the design of knowledge about new qualities, quality and effective management process and its dynamics, as well as the ability to originalize and expand knowledge about the content and characteristics of the existing process [4. 192]. Leadership competency modeling not only illuminates the content of the stages of a particular process, but also presents the interrelationships and sequences of the stages as a holistic system that simultaneously identifies and describes the functions of different social stakeholders in the process and assesses participants' effectiveness.

Describing, explaining, and predicting real system behavior are common functions of modeling, including: a) professional; b) psychological; c) social; d) socio-psychological, the importance of competencies is known in empathy, which affects the cognitive world in order to penetrate deeper into reality in the process of personal identification. In this regard, these competencies specific to the leader: mega (international organizations, transnational corporations), macro (central government bodies, including ministries), meso (organizations subordinate to the center, including social institutions, associations, unions), micro (interpersonal communication in primary organizations and small groups) appears in the system of relations of levels.

In my opinion, in determining the level of competence of the future "leader" formed under the influence of the above four different systems of relations, it is expedient to study the characteristics of the socio-psychological system "leader $\rightarrow$ community $\rightarrow$ person." After all, understanding a highly skilled manager is, first and foremost, understanding him, in which the competence of the person plays an important role.

In the research on the activities of the leader, for example, the issues of acmeological, communicative, psychological, professional, socio-psychological,socio-perceptive, conflict, ethnocultural competence: It has been studied using one of the "integrated", "ordered", "motivational-value", "socio-

anthropological", "behavioral”, "semisystemic", "cybernetic", "technological" and "digital transformational" approaches. 
According to traditional definitions given by scientists in the scientific literature [5; 376], competence is a set of standards in which an employee has a clear and unambiguous understanding of what is needed in order to perform his or her job very well, including skills, knowledge, and a range of concepts. The definition shows that there are causal links between all participants in the production, and allows us to understand that the external environment and the specific situation is an important factor in determining the behavior, spirituality of the person (manager and employee). For example, the psychological competence of a leader is assessed according to the "competence theory" by the following psychological condition, which includes a fourstage process, ie the transition from unexplained incompetence to unexplained competence. Theoretical coordination of the psychological competence of the middle level leader operating in the higher education system can be modeled as follows (see Figure 1).

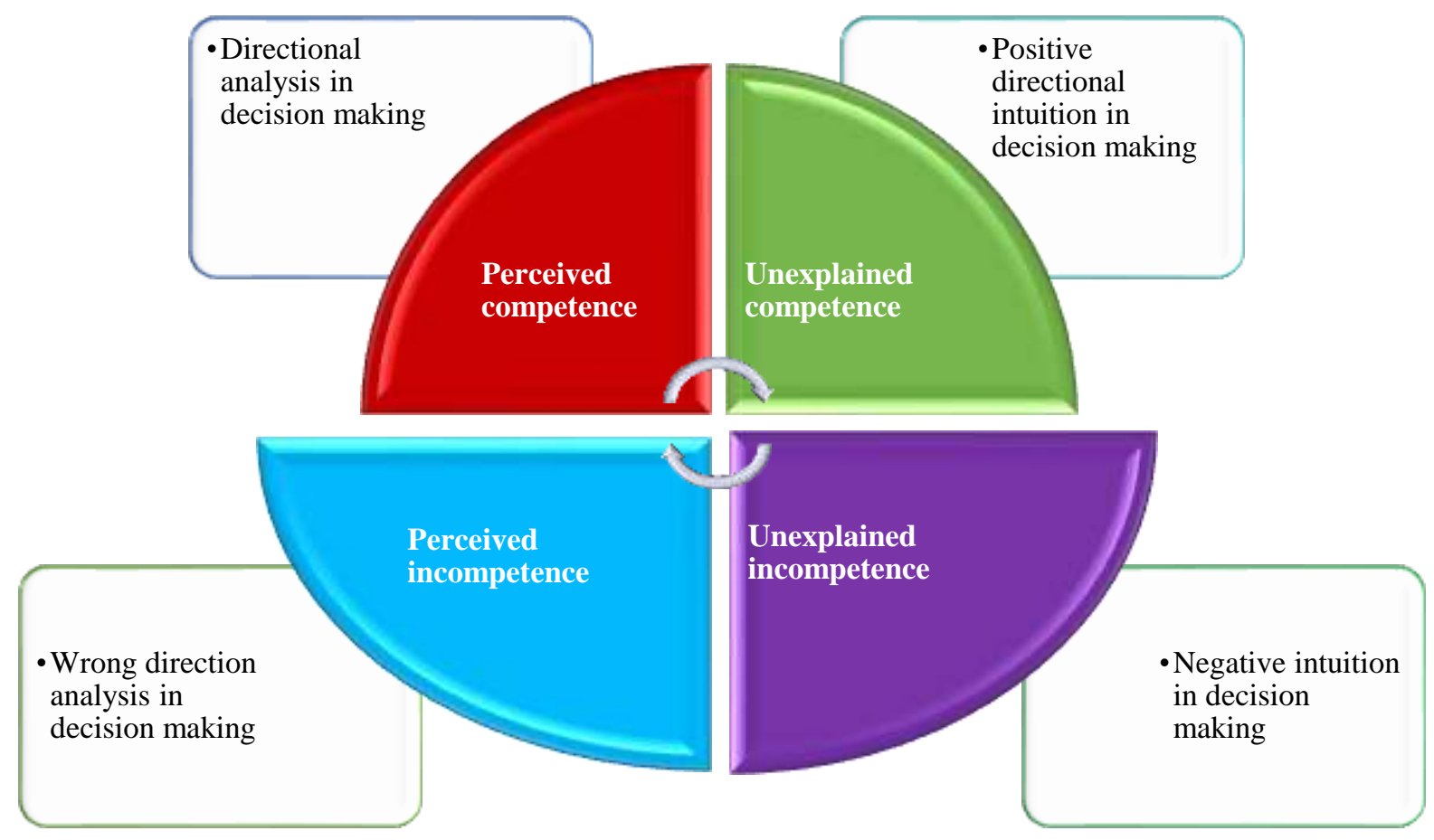

Figure 1. A Coordination Model Of A Leader's Psychological Competence In Making Management Decisions

In this coordination model can be seen mainly the socio-psychological mechanisms of professionalism, which represent the psychological competence of the leader in making management decisions. In my opinion, managerial professionalism is not only a condition of high professional results, but also a condition of the presence of the necessary psychological components, that is, an internal aspiration to work and an integral state of mental characteristics of the person. The essence of professionalism is inextricably linked with the solution of issues such as what leads a leader to greatness, what invaluable intuition he relies on, what motivates him to do it, what internal resources he voluntarily 
devotes to his work, this in turn depends on the level of psychological competence of the leader.

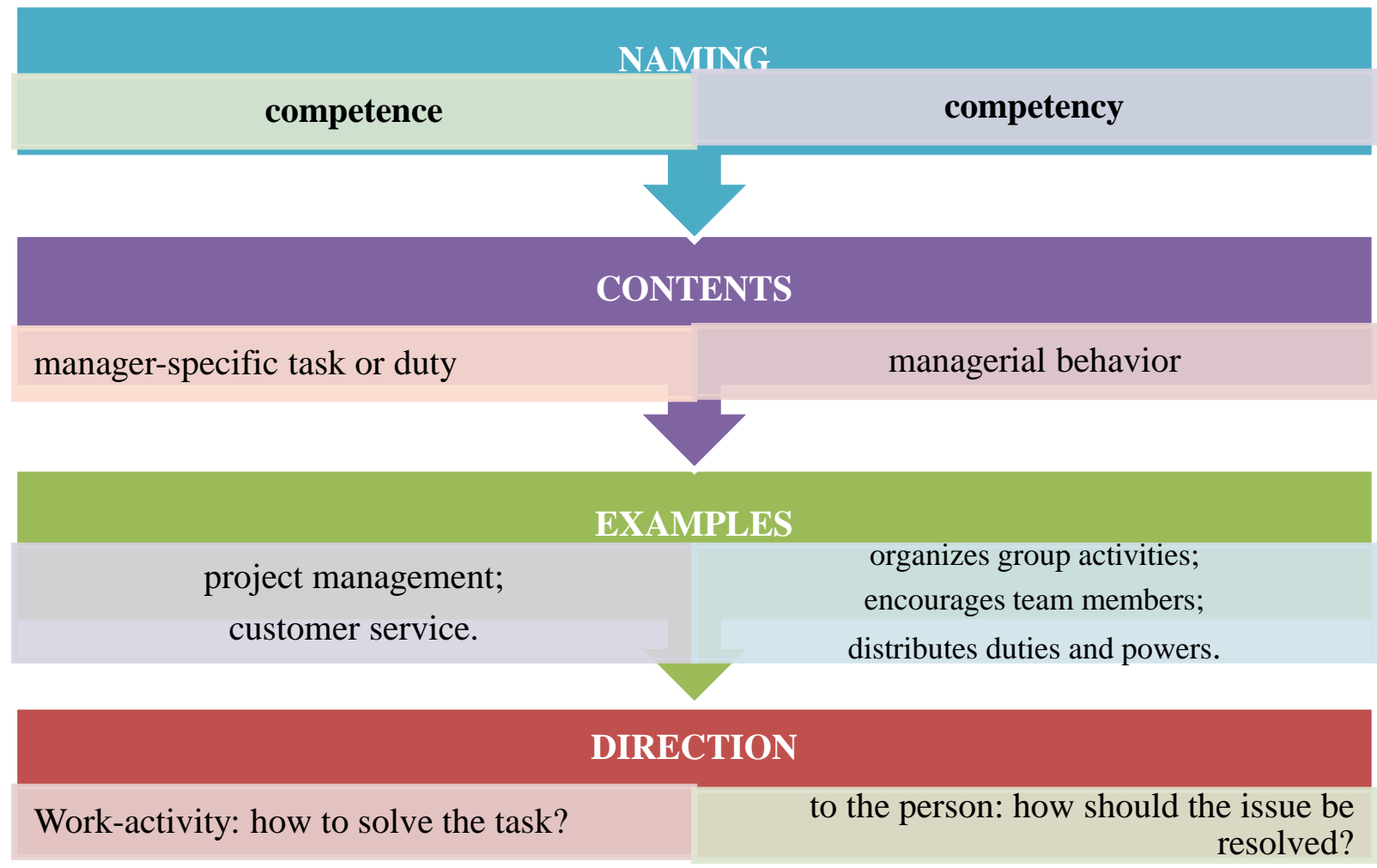

Figure 2. Model of competence and competencies of the mid-level management of the university

It is appropriate to call a cluster of observable behaviors of a leader in such circumstances a competency. For example, we can see this in the example of the leader's ability, interest, motivation.

For the last twenty-five years, the word "competency" has been interpreted as a concept that encompasses all the terms associated with management effectiveness. Eventually, such generalization led to a number of confusions and misunderstandings. In my opinion, the main reason for such misunderstandings may be the misapplication of the concepts of "competence" and "competence".
At present, the difference between these concepts is "What to achieve?" and "How are they achieved?" by finding answers to their questions. The essence of both concepts is determined by the following concept:

1. What? - "Competence" - is the result that determines the effective work process, ie the full performance of the functional duties and responsibilities of the middle manager.

2. How? - "Competency" - a model of behavior that includes the qualities of the mid-level leader, such as ability, interest, motivation, which he demonstrates in the performance of their functional duties and responsibilities [6.128]. 
In general, this model (see Figure 2) is useful, firstly, in creating a training and selection system aimed at developing the set of knowledge and qualities necessary for a midlevel leader, and secondly, in conducting intermediate attestation of mid-level leaders in accordance with established standards.

\section{CONCLUSION}

Based on the preliminary results of this study, aimed at determining the need for competence and competencies in the formation of the personality of the leader, the following scientific and theoretical conclusions can be made:

First, it can be said that competence is a standard that helps a leader evaluate his or her performance against the actions he or she has performed best. The reason is that such an assessment, in turn, leads to a positive change in the activities of the organization (economic entities) as a whole in the face of change. After all, the owners of success are the organization, the community, and certain individuals or leaders.

Second, when competency is studied within a particular person (leader), it helps to identify the strengths, qualities that a person needs to develop, and to identify the best, most effective ways to do the job, at the organizational level, it helps to fill the gaps left by the need for peer training and the advice provided.

Thirdly, based on the idea put forward in the above four-step theory, and again on the opinion of scientists who have conducted research in this field, competence - to ensure the continuity of the educational process, that is, to improve the skills of certain people (groups) and improve labor (study) activities, serves as a specific indicator in the formation of a professional person.

Fourth, there is almost no clear scientific research on the factors that shape the competence of the middle level leader in the local context, including the socio-psychological aspects of the scale of their impact on the basis of a complex approach. This situation is an urgent scientific problem in our country, the study of the psychological nature of the motivations that motivate leaders to acme and, accordingly, the development of educational programs that have both theoretical and practical character. In this regard, the results of research on the chosen topic are of great practical importance in determining the socio-economic prospects of the country and justifying the positive aspects of the path of development in the eyes of the world community.

\section{REFERENCES}

1. Lewin Kurt; Lippitt Ronald; White Ralph (1939). Patterns of aggressive behavior in experimentally created "social climates" // The Journal of Social Psychology. May, 1939, 10. - pp. 271-301.

2. http://stat.uz (application date: $25 \cdot 01.2020$ )

3. http://edu.uz (application date: 24.06.2020)

4. Shcherbakova T.N. Development of psychological competence of a professional: Textbook. Rostov n / a., 2007 .-p. 192.

5. Zazykin V.G; Karpenko A.S. Psychological competence of the leader: Textbook. Moscow: 2008. -p. 376.

6. Hayitov O.E; Umarova N.Sh. Theoretical and practical bases of developing the desire for 
The American Journal of Social Science and Education Innovations (ISSN - 2689-100x)

Published: August 10, 2020 | Pages: 55-61

Doi: https://doi.org/10.37547/tajssei/Volume02Issue08-09

professional growth in young people (on the example of the basis of genealogy):

monograph. Tashkent: 2011. -p. 128. 